\title{
Notch and $W n t / \beta$-catenin signaling pathway play important roles in activating liver cancer stem cells
}

\author{
Ronghua Wang ${ }^{1,2}$, Qian Sun ${ }^{1}$, Peng Wang ${ }^{1}$, Man Liu ${ }^{1}$, Si Xiong ${ }^{1}$, Jing Luo ${ }^{1}$, \\ Hai Huang', Qiang Du², David A. Geller ${ }^{2}$, Bin Cheng ${ }^{1}$ \\ ${ }^{1}$ Department of Gastroenterology and Hepatology, Tongji Hospital, Tongji Medical College, Huazhong University of Science \\ and Technology, Wuhan, China \\ ${ }^{2}$ Department of Surgery, Starzl Transplantation Institute, University of Pittsburgh School of Medicine, Pittsburgh, Pennsylvania, \\ USA
}

Correspondence to: Bin Cheng, e-mail: b.cheng@tjh.tjmu.edu.cn

Keywords: hepatocellular carcinoma, cancer stem cells, Notch, Wnt/ $\beta$-catenin

Received: July 22, 2015

Accepted: December 09, 2015

Published: December 31, 2015

\section{ABSTRACT}

Human hepatocellular carcinoma (HCC) is driven and maintained by liver cancer stem cells (LCSCs) that display stem cell properties. These LCSCs are promoted by the intersecting of Notch and Wnt/ $\beta$-Catenin signaling pathways. In this study, we demonstrate that LCSCs with markers CD90, CD24, CD13, and CD133 possess stem properties of self-renewal and tumorigenicity in NOD/SCID mice. The increased expression of these markers was correlated with advanced disease stage, larger tumors, and worse overall survival in 61 HCC cases. We also found that both Notch and $W n t / \beta$-catenin signaling pathways played important roles in increasing the stem-ness characteristics of LCSCs. Our data suggested that Notch1 was downstream of Wnt/ $\beta$-catenin. The active form of Notch1 intracellular domain (NICD) expression depended on $W n t / \beta$-catenin pathway activation. Moreover, Notch1 negatively contributed to Wnt/ $\beta$-catenin signaling modulation. Knock down of Notch1 with lentivirus N1ShRNA up-regulated the active form of $\beta$-catenin. Ectopic expression of NICD with LV-Notch1 in LCSCs attenuated $\beta$-catenin/TCF dependent luciferase activity significantly. In addition, there was a non-proteasome mediated feedback loop between Notch 1 and Wnt/ $\beta$-catenin signaling in LCSCs. The central role of Notch and the $W n t / \beta$-catenin signaling pathway in LCSCs may provide an attractive therapeutic strategy against HCC.

\section{INTRODUCTION}

Human hepatocellular carcinoma (HCC) is currently the fifth most common cancer and third leading cause of cancer death worldwide [1]. HCC contains heterogeneous cell populations, and only a small subset of cells, termed cancer stem cells (CSCs), have the ability to drive and sustain tumor growth [2-5]. CSCs are endowed with stem cell properties such as the capability for extensive proliferation, self-renewal, differentiation into non-tumorigenic cancer cells and recapitulation of the original tumor in immunocompromised mice. Therefore CSCs are considered to be a pivotal target for tumor eradication.

Various stem cell markers are essential for identifying LCSCs. Previous studies have demonstrated that cluster of differentiation CD133 [6], CD90 [7], CD13 [8], CD24 [9], CD44 [10] and Epithelial cell adhesion molecule (EpCAM) [11] are cell surface markers for LCSCs. A multiple markers hypothesis has been suggested for CSCs in breast, pancreatic cancers and HCC [12, 13]. Yang et al demonstrated that the CD90+CD44+ phenotype of liver CSCs may explain the aggressive growth pattern of HCC [7]. However, it remains unclear whether $\mathrm{HCC}$ patients with these markers share similar or distinct features, and whether combined detection of those markers would be more significant in predicting the prognosis of clinic-pathological characteristics in patients.

Understanding the pathways that regulate CSC self-renewal, differentiation and tumorigenicity may thus be critical to the development of effective anticancer therapies [14]. Developmental pathways such as Notch [15], Hedgehog [16] and $\mathrm{Wnt} / \beta$-catenin [17-19] play important roles in normal stem cell function and are frequently altered in cancers. Notch activation promotes cell proliferation and the formation of stem cell-like colonies in human glioma 
cells [20], colon cancer [21] and breast cancer stem cells [22]. The Wnt/ $\beta$-catenin pathway augments self-renewal capacity and inhibits the differentiation of colorectal and liver cancer stem cells [23-25]. We have previously demonstrated that $\mathrm{Wnt} / \beta$-catenin signaling is downstream of the Notch pathway in regulating proliferation and malignant transformation of hepatic cell line L02/ HBx [26]. However, recent studies reported that Notch is downstream of Wnt and negatively titrating active $\beta$-Catenin protein levels in stem/progenitor cells and colorectal cancer $[27,28]$. As a result, it remains elusive whether Notch activity has a positive or negative effect on $\mathrm{Wnt} / \beta$-catenin and how they affect each other in regulating the self-renewal of liver CSCs.

In this study, we found that simultaneous high expression of 4 different markers (CD90, CD24, CD13, CD133) correlates with poor prognosis in a total of 61 cases of $\mathrm{HCC}$ patients and serves as a promising predictor the prognosis of HCC patients. We also found that Notch and $W n t / \beta$-catenin signaling pathways play a crucial role in maintaining the self-renewal of CD90, CD24, CD13, CD133 high expressed sphere-forming LCSCs. Notch1 may be downstream of $\mathrm{Wnt} / \beta$-catenin signaling, and Notch1 negatively regulates $\mathrm{Wnt} / \beta$-catenin signaling. There may also be a non-proteasome mediated feedback loop between those two signaling pathways.

\section{RESULTS}

\section{Expression of CD90, CD24, CD13 and CD133 in liver cancer cells correlates with poor prognosis in patients with $\mathrm{HCC}$}

To investigate whether cancer stem cell markers were over-expressed in HCC specimens, we retrospectively evaluated the expression levels of five cancer stem cell markers (CD90, CD44, CD133, CD13 and CD24) using IHC in 61 matched human HCC specimens and adjacent liver specimens. The markers CD90, CD44, CD133, CD13, and CD24 were present diversely in all HCC samples. By contrast, their expression in non-tumor (NT) liver tissues was almost absent (Supplementary Figure S1). The representative immunostaining of markers in tumor and uninvolved adjacent non-tumor tissues, and the pattern and intensity of staining for potential cancer stem cell markers in hepatocellular carcinoma specimens are shown in Supplementary Figure S1.

Next, we investigated the clinical-pathologic correlation of those five markers expression. Our data showed that patients whose tumors over-expressed CD133 or CD13 had significantly shorter overall survival than those with lower CD133 or CD13 expression ( $p=0.044$ and $p=0.013$, respectively, log-rank test, Figure $1 \mathrm{~A}$ and $1 \mathrm{~B})$. Consistent with that finding, patients with CD133 or CD13 over-expression had shorter diseasefree survival, though this finding with respect to CD133 did not reach statistical significance $(p=0.129$ and $p=0.024$, respectively, log-rank test). Patients whose tumors had significantly higher CD13 expression presented at more advanced TNM Stages ( $p=0.016$, One-way ANOVA analysis, Figure 1C) compared with their low CD13 expression counterparts. Patients with high CD90 expression also had significantly poorer differentiation status ( $p<0.05, t$ test, Figure 1D). Univariate analyses of clinical pathologic correlations of all 5 markers expression in 61 HCC patients were shown in Supplementary Table S1. In summary, over-expression of LCSCs markers-CD90, CD44, CD133, CD13, and CD24 - correlated with poorer differential status and shorter overall/disease-free survival.

Furthermore, we investigated the potential correlation between the expression of 4 different markers (CD90, CD24, CD13 and CD133) and the clinical outcomes of HCC patients. In a Kaplan-Meier survival analysis, patients with CD90CD24CD13CD133+/high primary tumors displayed worse overall and disease-free survival (estimated mean $=16$ months) as compared to those patients with CD90CD24CD13CD133-/low primary tumors (estimated mean $=58$ and 45 months, respectively, log-rank test, $p=0.0062$ and 0.0095 , respectively; Figure 1E). We also analyzed Kaplan-Meier survival, patients in stage I/II with CD90CD24CD13CD133+/high primary tumors displayed worse overall and disease-free survival as compared to those patients in stage I/II with CD90CD24CD13CD133-/low primary tumors (estimated mean $=54$ and 13 months, respectively, log-rank test, $p<0.0001$ and $p=0.0002$, respectively, Supplementary Figure S2A). In terms of disease-free survival or overall survival, however, there were no statistical differences between other combinations of high expression and the low expression group, such as CD90CD44CD13CD133+/ high, CD90CD44CD24CD133+/high and CD90CD44CD 13CD24+/high (data not shown). Our data showed that increased CD90CD24CD13CD133+/high expression in HCC not only correlated with advanced disease stage but also was associated with larger tumor size. Increased CD90CD24CD13CD133+ expression in HCC was more associated with higher tumor stages (TNM stages III or IV) than with lower tumor stages (TNM stages I or II) $(p=0.011$; Table 1$)$. The information of 17 patients with high CD90CD24CD13CD133 over-expression was shown in Supplementary Table S2. Furthermore, the logistic regression analysis showed that CD90CD24CD13CD133+ expression was inversely correlated with differentiation status in these $61 \mathrm{HCC}$ patients $\left(\mathrm{OR}=0.188, X^{2}\right.$ test, $p=0.041$, Table 1). Altogether, Over-expression of CD90, CD24, CD13 and CD133 in HCC correlated with more aggressive tumor behaviors and worse clinical outcomes in HCC patients. 


\section{Sphere-forming HCC cells possessed characteristics of cancer stem cells and the capacity to metastasize in vivo and in vitro}

We then enriched liver cancer stem cells in a three-dimensional sphere condition. We've analyzed the expression of all markers in 3rd passage of sphereforming cells simultaneously by flow cytometry, and demonstrated that all the markers (CD90, CD24, CD133 and CD13) in sphere-forming cells were up-regulated. The expression of CD90, CD24, CD133 and CD13 were increased to $12.2 \%, 15.9 \%, 15.2 \%$ and $80.6 \%$ respectively, comparing to the parental cells, in which the expression of all markers are less than $2.6 \%$ (Supplementary Figure S2B). We also confirmed that the expression of CD90, CD24, CD13 and CD133 were approximately 26.7-fold, 6.9-fold, 2.6-fold and 8.8-fold higher respectively, compared with the parental cells. $(p<0.001, t$ test, Figure 2A and Supplementary Figure S3A).
A

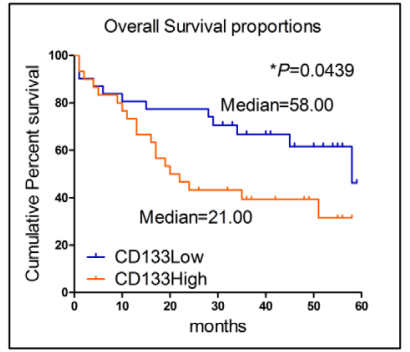

B

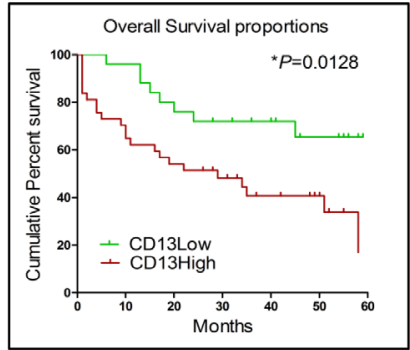

C

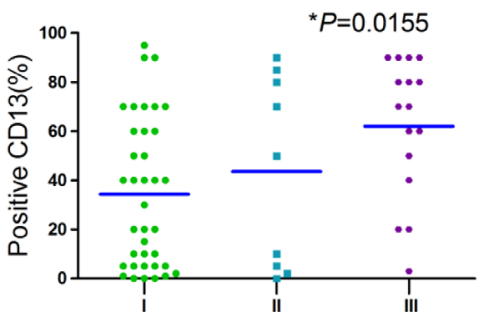

E

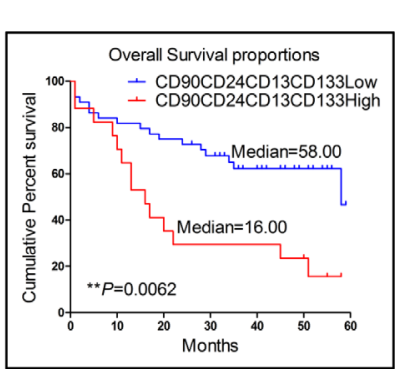

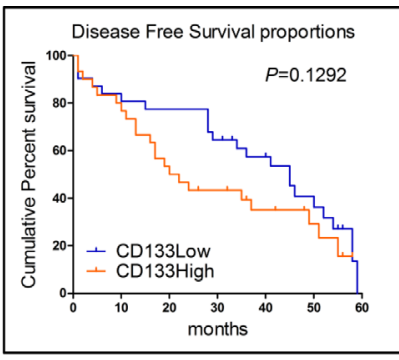

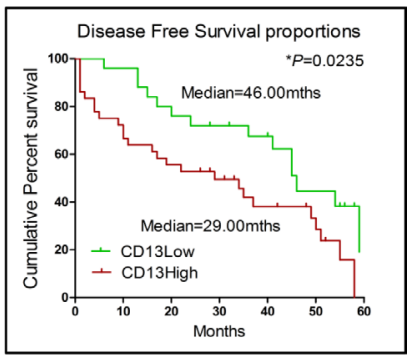

D

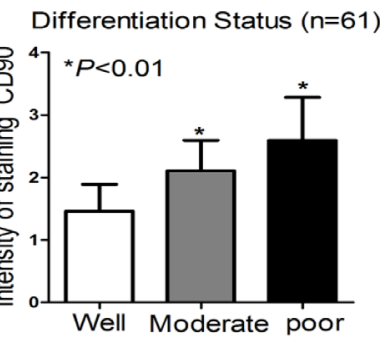

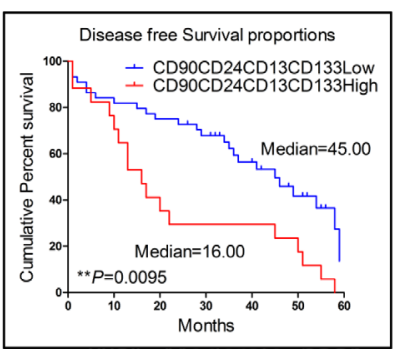

Figure 1: Expression of CD90, CD24, CD13 and CD133 in liver cancer cells correlated with poor prognosis in patients with HCC. (A and B) Kaplan-Meier analyses for overall and disease-free survival were compared according to the CD133 and CD13 expression in tumor tissues. (C) Patients who had higher advanced TNM Stages HCC ( $p=0.0155$, One-way ANOVA analysis) presented significantly higher CD13 expression. (D) Patients with high CD90 expression had a significantly poorer differentiation status $(p<0.05, t$ test). (E) Kaplan-Meier survival analysis of patients demonstrated that CD90CD24CD13CD133+ primary tumors displayed worse overall and disease-free survival. (log-rank test, $p=0.0062$ and 0.0095 ). 
Table1: Multivariate analyses of clinico-pathologic correlation of CD90CD24CD13CD133 expression in $61 \mathrm{HCC}$ patients

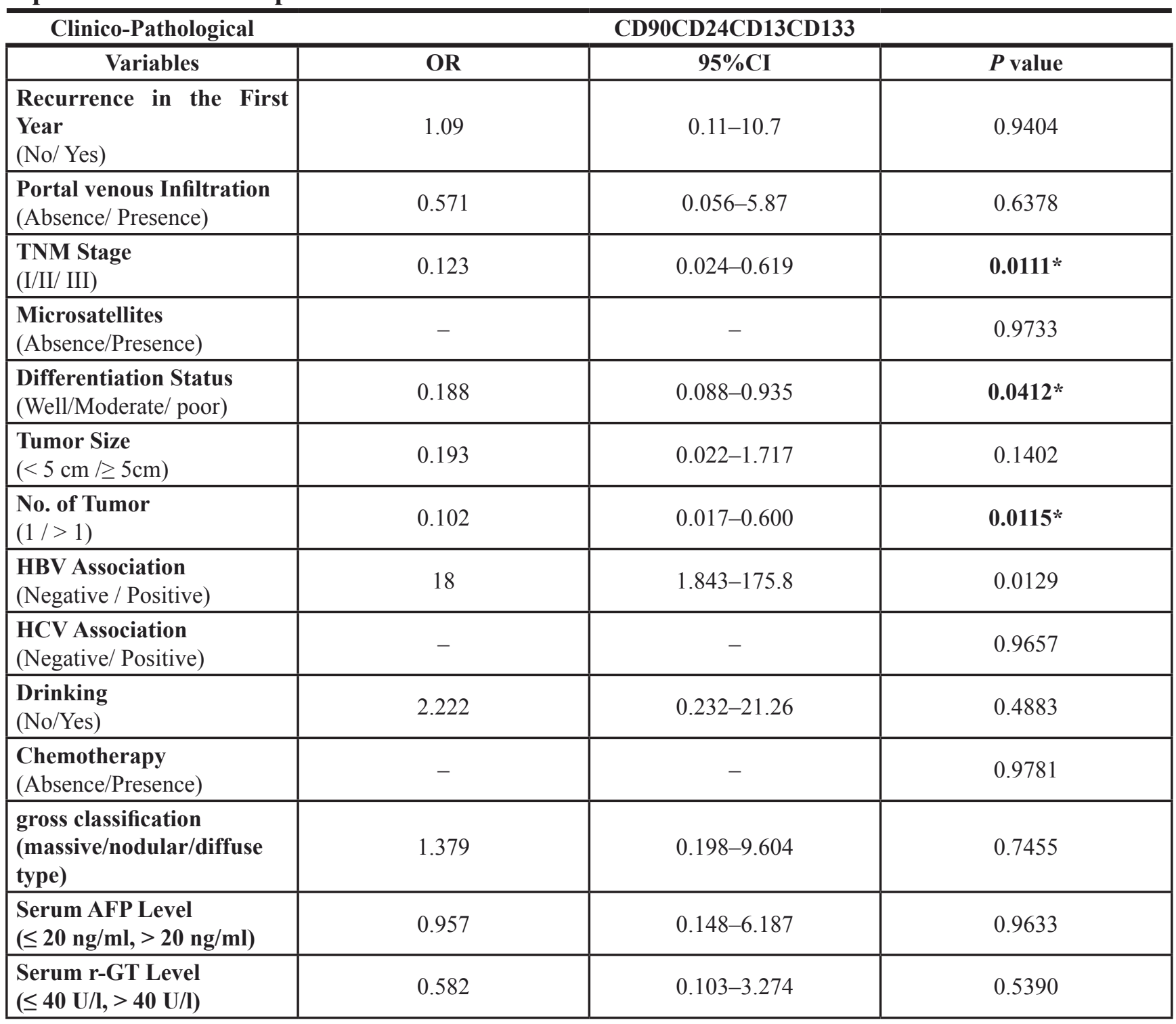

${ }^{*} P<0.05$, Significant difference (logistic regression, Chi-Square test).

${ }^{* *} p<0.01$, Significant difference (logistic regression, Chi-Square test).

Cancer stem cells (CSCs) are believed to possess the stem/progenitor properties of self-renewal [29], relative quiescence, tumorigenicity [30] and metastasis in immunodeficient mice [31]. In our study, colony formation assay revealed that sphere-forming cells derived from $\mathrm{PLC} / \mathrm{PRF} / 5$ and Huh7 proliferated at a significantly higher rate than parental cells $(p=0.0044$ and $p=0.0071$, respectively, $t$ test, Figure 2B and Supplementary Figure S3B). Additionally, to determine the tumorigenicity in vivo, sphere-forming HCC cells and parental cells were inoculated subcutaneously into NOD/SCID mice. Higher tumor incidence was observed in the sphere-forming $\mathrm{HCC}$ cells group (Figure 2C). Furthermore, as few as 1000 sphere-forming SMMC7721 (high potential of invasion and metastasis) and PLC/PRF/5 (comparatively low potential of invasion and metastasis) cells were sufficient for initial and consistent tumor development in NOD/SCID mice from $14 \mathrm{~d}$ and $37 \mathrm{~d}$, respectively (Supplementary Table S3), which supports the greater self-renewal capability of sphere-forming HCC cells. Moreover, the expression of CD44, CD13 and CD24 is statistically higher in xenografts derived from sphere-forming PLC/PRF/5 and SMMC7721 cells, compared with the parental counterparts by IHC (Supplementary Figure S3C). Next, to determine whether sphere-forming HCC cells had other intrinsic properties of stem cells, we evaluated the expression of certain "stemness"-associated genes (NANOG, OCT3/4, SOX2 and BMI-1) [32-35] that are crucial in pathways and programs for establishing and maintaining stem cell-like characteristics. With qPCR and 
western blotting analysis, we found that $\mathrm{CD} 90, \mathrm{CD} 24$, CD13 and CD133 over-expressed fractions purified from $\mathrm{PLC} / \mathrm{PRF} / 5$ cells had a general over-expression of these "stemness"-associated genes (Figure 2D).

To compare the relative quiescence of sphereforming HCC cells and parental cells, cell cycle and apoptosis was measured by flow cytometry. We demonstrated that the proportion of sphere-forming PLC/ $\mathrm{PRF} / 5$ cells in the G0/G1 phase was distinctly increased, while cells in the S and G2-M phase were significantly decreased, compared to the parental counterparts $(P<0.01$, Supplementary Figure S3D $)$. Furthermore, our results showed that the percentage of apoptotic cells in sphere-forming $\mathrm{PLC} / \mathrm{PRF} / 5$ cells was significantly decreased $(8.76 \pm 0.39 \%$ versus $2.52 \pm 0.35 \%$, Supplementary Figure S3E), which means that sphereforming cells induced cell cycle arrest and anti-apoptosis.

Vascular invasion is believed to be an important pathologic feature determining HCC metastasis and tumor recurrence [36, 37]. In our study, six out of eight (75\%) patients with vascular invasion exhibited in CD90CD24CD13CD133+/high expression patients group (Supplementary Table S2), suggesting that CD90CD24CD13CD133+/high HCC cells were endowed with metastatic features. These data support the hypothesis that CD90CD24CD13CD133+/high CSCs represent a distinct invasive population that contributes to tumor metastasis. To test this hypothesis, we first isolated parental cells and sphere-forming cells from PLC/PRF/5 and examined their invasive abilities by using transwell migration assay. Compared to parental cells, sphereforming cells displayed approximately 5.49-fold migration efficiency in transwell migration assay $(p<0.0001, t$ test, Figure $2 \mathrm{E})$. To test the in vivo metastatic role of sphereforming HCC cells, an experimental metastasis model was employed by injecting subcutaneously $5 \times 10^{5}$ sphereforming or parental SMMC-7721 cells into NOD/SCID mice. After 40 days, the formation of tumor foci in the lungs was evaluated with exploratory thoracotomy. $66 \%$ mice injected with sphere-forming SMMC-7721 cells showed tumor formation in the lungs, whereas none of the mice injected with parental cells showed tumor formation in the lungs (Figure 2F and Supplementary Table S3). Furthermore, the mRNA and protein expression levels of EMT-related genes and transcription factors Vimentin, Snail and Twist, significantly increased in sphere-forming PLC/PRF/5 cells (Figure 2G). Meanwhile, HCC cells with high CD90, CD24, CD44 or CD133 expression in patients' specimens significantly clustered around or in venous or lymphatic vessels invasion (Supplementary Figure S4A). Consistently, higher CD90CD24CD13CD133 expression group positively correlated with worse TNM Stage significantly (Table1). Taken together, sphere-forming HCC cells expressed stem cell-associated genes, possessed the stem/progenitor properties, including extensive proliferation, exhibited an increased potential to self renew and metastasis in vitro and in vivo.

\section{Notch and Wnt//-catenin signaling pathway components were up-regulated in sphere-forming liver cancer stem cells}

We found that the high expression of Notch1 in HCC clinical specimens is associated with venous infiltration and poor prognosis (Data not shown). To investigate the molecular mechanisms involved in self-renewal and metastasis activity of sphere-forming LCSCs, the mRNA and protein expression levels of Notch signaling pathway components (NOTCH1, HES1 and HEY1) and Wnt/ $\beta$-catenin signaling pathway components (Axin2, TCF3, CyclinD1 and MYC) were assessed. We found that the Notch and Wnt/ $\beta$-catenin signaling pathway components are up-regulated in sphere-forming LCSCs HCC cells, compared to the parental counterparts (Figure 3A and 3B). To further demonstrate the biological function of Notch and Wnt/ $\beta$-catenin signaling pathway in the self-renewal activity of sphere-forming LCSCs, we used a Notch-specific inhibitor, the $\gamma$-secretase inhibitor (DAPT) and a Wnt/ $\beta$-catenin-specific inhibitor, tankyrase $1 / 2$ inhibitor (XAV939), to block the function of the Notch and $W n t / \beta$-catenin signaling pathway, respectively (Figure 3C and 3D).

\section{Notch and Wnt/ $\beta$-catenin signaling pathways promoted stem-ness characteristics and metastasis potential in sphere-forming liver cancer stem cells}

To investigate further the roles of Notch and $\mathrm{Wnt} / \beta$-catenin signaling pathways in maintaining the stem-ness characteristics and metastasis ability in sphere-forming LCSCs, we performed a sphere formation and colony formation assay. We demonstrated that DAPT, XAV939 and DAPT + XAV939 together could significantly inhibit sphere formation and colony formation in sphere-forming LCSCs derived from PLC/PRF/5 cells (Figure 4A and 4B). Furthermore, sphere-forming LCSCs derived from PLC/PRF/5 cells were subcutaneously inoculated into NOD/SCID mice, when the tumors reached $4 \mathrm{~mm}$ in diameter, the mice were injected intratumorally with DAPT, XAV939 and DAPT + XAV939 (Supplementary Table S4). We observed that both DAPT and XAV939 together could significantly inhibit the initiation and consistent tumor development in NOD/SCID mice after injected intratumorally in mice (Figure 4C and Supplementary Figure S4B). Additionally, we demonstrated that inhibition of DAPT, XAV939 and DAPT+XAV939 together could obviously attenuate the expression of the Notch intracellular domain (NICD) and $\beta$-catenin in vivo using IHC 
(Supplementary Figure S4B). Taken together, these results suggested that both Notch and Wnt/ $\beta$-catenin signaling pathway play important roles in the regulation of self-renewal and the tumorigenicity of sphere-forming LCSCs. Consistently, upon Notch or/and Wnt/ $\beta$-catenin inhibited, stemness-associated genes (NANOG and SOX2) were significantly down-regulated (Figure 4D, $* p<0.05, t$ test). Furthermore, our data demonstrated that the cancer stem cells surface markers phenotype, CD90, CD44 and CD133 decreased when Wnt/ $\beta$-catenin and Notch were blocked (Figure 4E), indicating that Notch or/and $\mathrm{Wnt} / \beta$-catenin blocking resulted in a differentiation of sphere-forming LCSCs. In addition, the downregulation of Notch or/and Wnt/ $\beta$-catenin with DAPT or/ and XAV939 in sphere-forming LCSCs could significantly inhibit cell migration (Figure 4F). Inhibition of Notch or/ and Wnt/ $\beta$-catenin with DAPT or/and XAV939 could decrease the expression of EMT-associated transcription factors, Vimentin, SNAIL1 and TWIST1 (Figure 4G, $* p<0.05, t$ test). Collectively, these results suggested that both Notch and Wnt/ $\beta$-catenin were essential factors for maintaining the self-renewal and metastasis of LCSCs.

\section{Notch1 was downstream of Wnt/ $\beta$-catenin signaling in liver cancer stem cells}

Intriguingly, it has been demonstrated that Notch is downstream of Wnt in colorectal cancer cells through $\beta$-catenin-mediated transcriptional activation of the Notch-ligand Jagged1 [28]. To study the Notch and $\mathrm{Wnt} / \beta$-catenin signaling pathway in sphere-forming liver cancer stem cells, we first employed XAV939 to block Wnt/ $\beta$-catenin pathway. And the Notch signaling pathway components (NICD, Hes1 and Jagged1) were dramatically down-regulated 0.51 -fold, 0.43-fold and 0.50-fold, respectively ( $p<0.05$, Figure $5 \mathrm{~A}$ ) in set of the inhibition of Wnt $\beta$-catenin by XAV939. On the contrary, indeed activation of $\mathrm{Wnt} / \beta$-catenin signaling by Wnt ligand Wnt3a or 6-bromoindirubin-3'-oxime (BIO), specifically inhibits GSK3 activity and inactivates the destruction complex, resulted in the dose-dependent increase in $\mathrm{TCF} / \beta$-catenin-dependent transcriptional activity (Figure 5B and 5C, respectively), accumulation of active $\beta$-catenin (Figure 5D), NICD and Jagged1 (Figure 5E). Taken together, Notch1 positively correlated with the activation of Wnt/ $\beta$-catenin, suggesting that Notch1 may be downstream of Wnt/ $\beta$-catenin signaling in sphere-forming liver cancer stem cells.

\section{6. $\beta$-catenin protein levels were diminished by Notch1 in liver cancer stem cells}

To determine if Notch also regulates $\beta$-catenin protein levels in sphere-forming LCSCs, we blocked Notch endoproteolysis, which is mediated by the presenilin $\gamma$-secretase complex by DAPT, and investigated
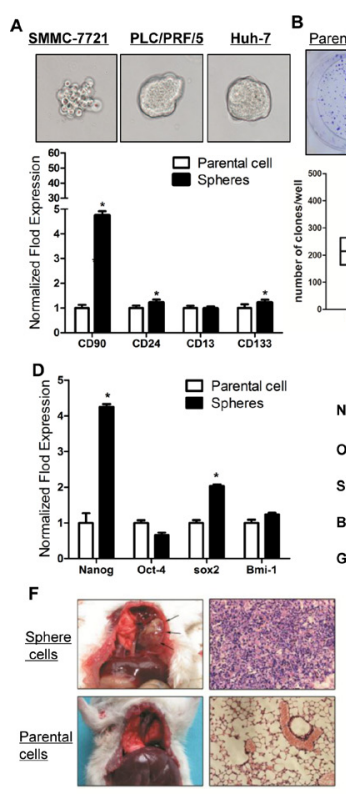
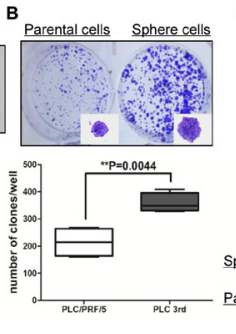

c
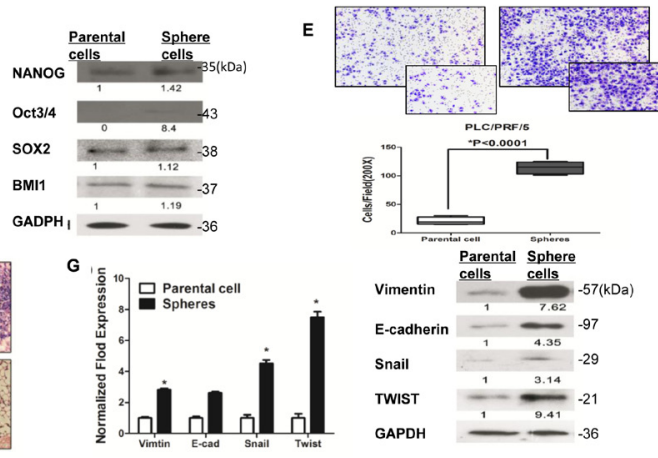

Figure 2: Sphere-forming HCC cells possessed characteristics of cancer stem cells and capacity to metastasize in vivo and in vitro. (A) The PLC/PRF/5 sphere-formation cells express higher cancer stem cells markers (CD90, CD24, CD13, CD133) ( $p<0.05, t$ test). The representative spheres from HCC cell lines also shown on the top. (B) The PLC/PRF/5 sphere-formation process higher colony formation efficiency ( $p=0.044, t$ test). (C) Efficiency of tumor formation and tumor volume of sphere-forming HCC cells (right black arrows) from PLC/PRF/5 and their parental cells (left white arrows) in NOD/SCID mice. (D) RT-PCR and western blotting for the detection of stemness-associated genes over-expressed in PLC/PRF/5 sphere-formation cells. (E) Transwell migration assay in parental cells and sphere-forming HCC cells (magnification times, 100X and 200X, respectively). (F) Representative pulmonary metastasis of sphere-forming SMMC-7721 cells in NOD/SCID mice. Hematoxylin and eosin staining of a pulmonary metastasis tumor (right parts). (G) The mRNA and protein expression level of EMT-related genes in sphere-forming SMCC-7721 cells. 
the regulation of $\beta$-catenin. Unexpectedly, we found that LCSCs treated with the $\gamma$-secretase inhibitor (GSI), DAPT, had a significant reduction of active $\beta$-catenin activity and protein levels in a dose-dependent fashion (Figure 6A). Moreover, the activation of $\mathrm{Wnt} / \beta$-catenin signaling by BIO ( $2 \mathrm{uM})$ or Wnt3a $(100 \mathrm{ng} / \mathrm{ml})$ can rescue $\gamma$-secretase inhibitor (BMS-708163)-induced suppression of $\beta$-catenin dependent luciferase activity (Figure 6B and Supplementary Figure S4C). Conversely, the reduced Notch1 levels which were knocked out by lentiviral vector-mediated RNAi, LV-N1ShRNA (Figure 6C), did not affect the levels of total $\beta$-catenin protein but resulted in an increase in the dephosphorylated, transcriptionally active form of $\beta$-catenin protein (Figure 6D). We also found that LV-N1ShRNA LCSC exhibited significantly lower $\beta$-catenin/TCF dependent luciferase activity than controls, when stimulated with Wnt3a or BIO (Figure 6E). Finally, to confirm the Notch negatively regulation on $\beta$-catenin protein levels in LCSCs, we used lentiviral particles express NICD (Lv-Notch1) to over-express the cleavaged active-Notch1 levels (Figure 6F) in LCSCs and found a prominent decrease in $\beta$-catenin/TCF dependent luciferase activity (Figure $6 \mathrm{G}$ ) and active $\beta$-catenin protein levels (Figure $6 \mathrm{H}$ ). These results indicated that Notch1 negatively contributes to $\mathrm{Wnt} / \beta$-catenin signaling modulation and is probably not proteasome mediated, which supports the earlier evidence showing Numb dependence and potential involvement of the lysosome [27].

\section{DISCUSSION}

There is emerging evidence that HCC is driven and maintained by LCSCs that display stem cell properties. Therefore, tracing and "destemming" CSCs may be an effective strategy for treating $\mathrm{HCC}$ and improving patient outcomes.

In this study, we found that HCC patients with different CSC markers (CD133, CD90, CD13, CD24 or CD44) possessed distinct clinic-pathological features, suggesting that these cells with different cancer stem cell markers may be present in an identical HCC population. Furthermore, we have demonstrated that increased CD90CD24CD13CD133 expression in HCC not only correlates with advanced disease stage but also with larger tumor size and worse overall survival. This correlation suggests that CD90CD24CD13CD133+/high tumor cells have the potential to re-establish tumor growth in patients. Recently, several studies have also reported that successive passages of sphere-forming cells derived from mammary carcinoma cell line [38], pancreatic cancers [30] and cervical cancer [39, 40], displayed progressive cancer stem cells enrichment and different markers (CD90 and

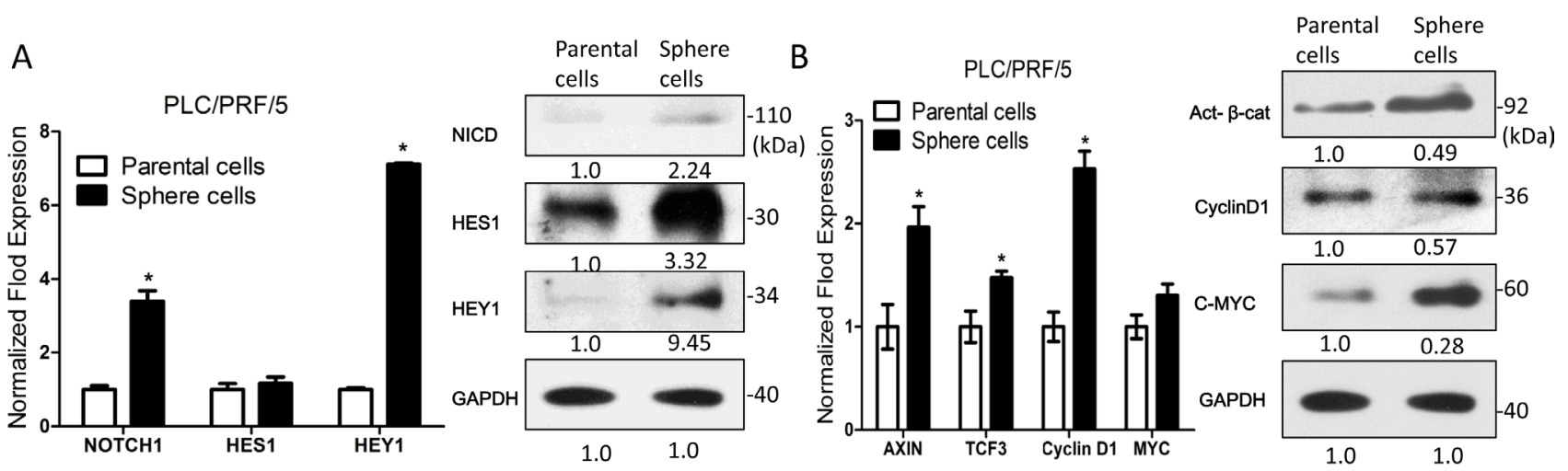

C
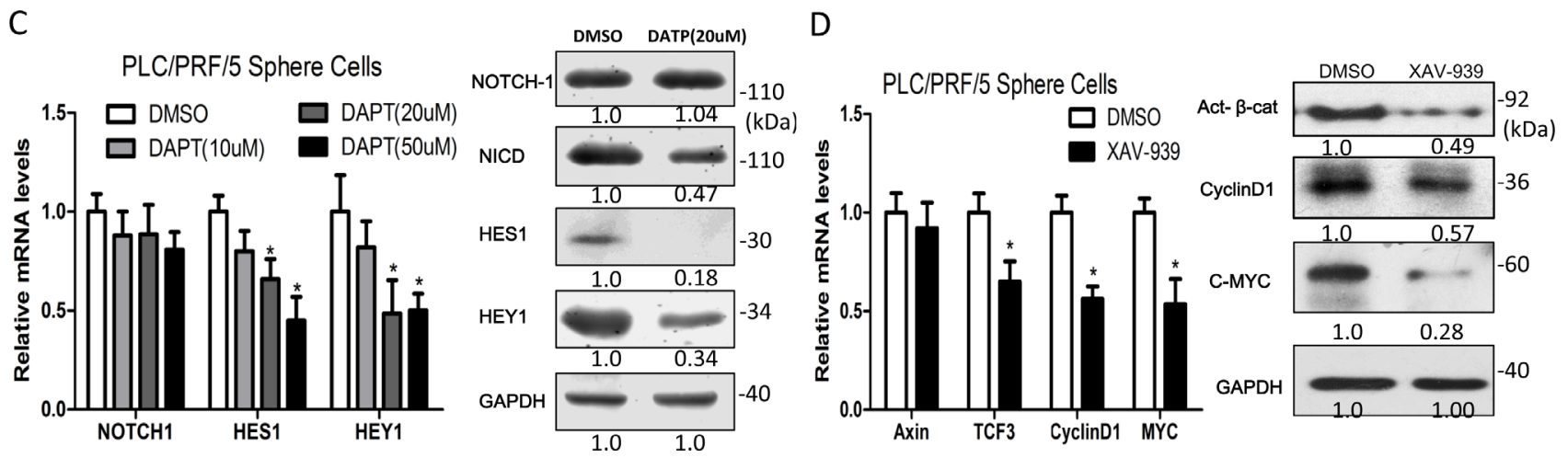

Figure 3: Notch and Wnt/ $\beta$-catenin signaling pathway components are up-regulated in sphere-forming liver cancer stem cells. (A and B) The mRNA and protein expression levels of Notch and Wnt/ $\beta$-catenin signaling pathway components are up-regulated in sphere-forming liver cancer stem cells. (C and D) Notch and Wnt/ $\beta$-catenin signaling pathway were inhibited by $20 \mu \mathrm{M}$ of DAPT and $20 \mu \mathrm{M}$ XAV939, respetctively. 
CD133) over-expression. Therefore, we hypothesized that liver cancer stem cells might concomitantly express two or more LCSCs markers instead of only one LCSCs marker.

To determine whether sphere-forming (CD90CD24CD13CD133+/high) HCC cells were LCSCs, we detected the stem-ness associated characteristics. Our data demonstrated that the sphere-forming HCC cells possessed progressively increasing self-renewal and tumor-initiating ability in vitro and in vivo. Furthermore, we found that CD90, CD24, CD44 or CD133 over-expression was also positively correlated with vascular infiltration, which is an important clinicpathologic feature of HCC metastasis. The identification

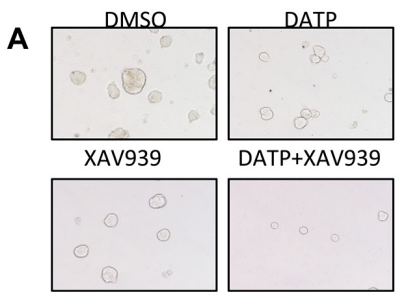

PLC/PRF/5 Sphere Cells
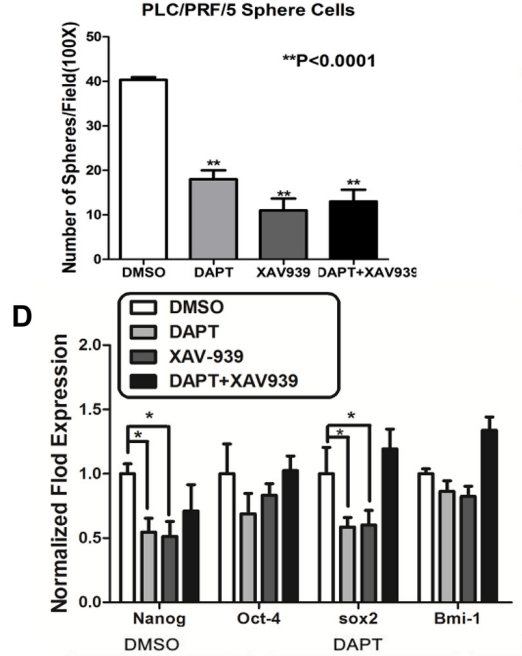

B

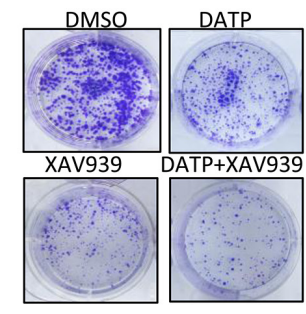

PLC/PRF/5 Sphere Cells
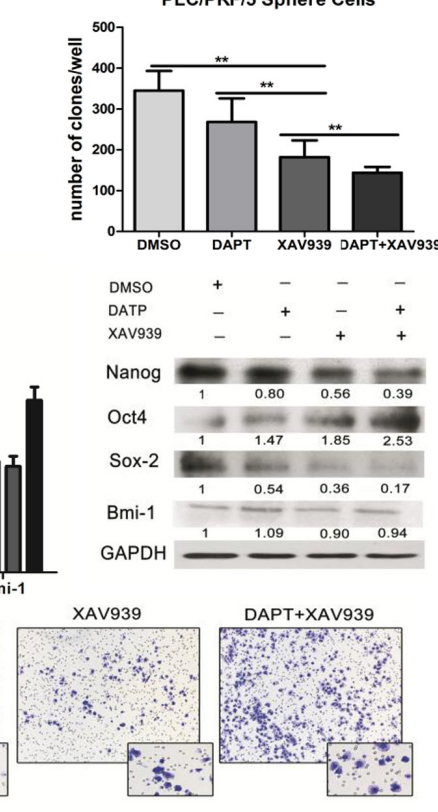

AV939

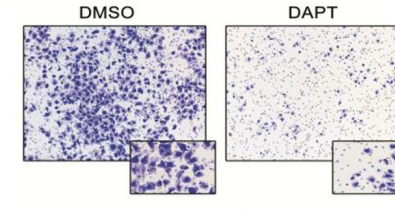

PLC/PRF/5-3rd sphere
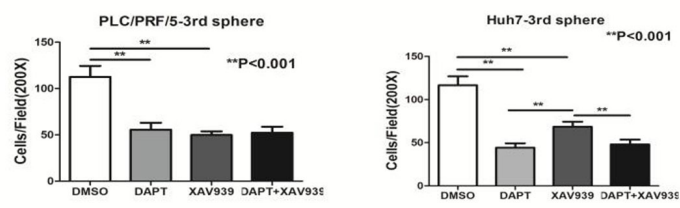

of sphere-forming HCC cells as a subpopulation involved in the CSC self-renewal of HCC might open up new perspectives for treatment.

Intriguingly, increasing evidence has shown that both Notch and Wnt signaling may play critical roles in the self-renewal of different CSCs [27, 41]. In particular, Notch signaling promotes the formation of cancer stem cells in human glioma [20]_and inhibition of Notch signaling reduces primary tumor side population in breast cancer stem cells [42]; similarly, activation of Wnt1 signaling accelerates the proliferation rate and spheroids formation of gastric CSCs [43], while silencing of $\beta$-catenin by small interfering RNA could synergize

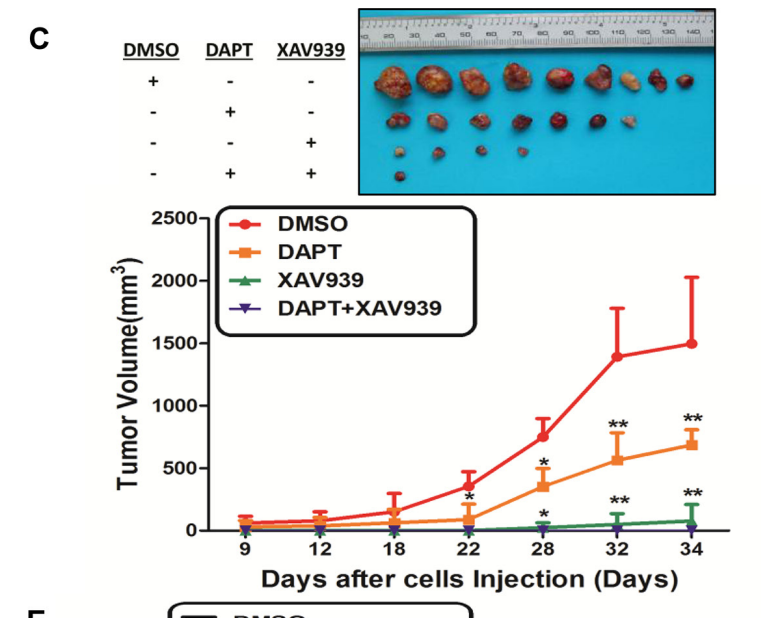

E
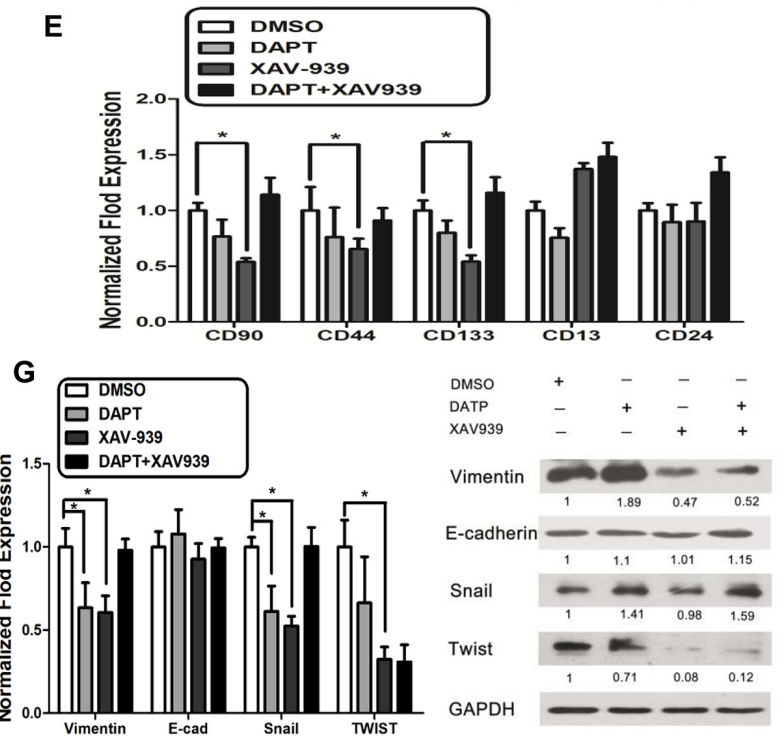

Figure 4: Notch and Wnt/ß-catenin signaling pathways promoted stem-ness characteristics and metastasis potential in sphere-forming liver cancer stem cells. (A and B) Sphere formation and colony formation ability (A) and efficiency of tumor formation (B) in sphere-forming PLC/PRF/5 decreased when inhibiting Notch and Wnt/ $\beta$-catenin signaling pathway by $20 \mu \mathrm{M}$ of DAPT and $20 \mu \mathrm{M}$ XAV939. (C) Efficiency of tumor formation and tumor volume of sphere-forming LCSCs were decreased by the blocking of Notch and Wnt/ß-catenin. (D) Stemness-associated genes (NANOG and SOX2) were significantly down-regulated upon Notch or/and Wnt/ $\beta$-catenin inhibited ( $p<0.05, t$ test). (E) The cancer stem cells surface markers phenotype, CD90, CD44, CD133, were diminished by DAPT or XAV-939. But the decrease observed with DATP and XAV939 combined was no more than that observed by either individual treatment. (F and G) The metastasis capacity in transwell assay and EMT-related genes (Vimentin, Snail and Twist) were decreased in sphere-forming PLC/PRF/5 after inhibition of Notch and Wnt/ $\beta$-catenin signaling pathway. Error bars represent standard deviation (SD) from at least three independent experiments. 

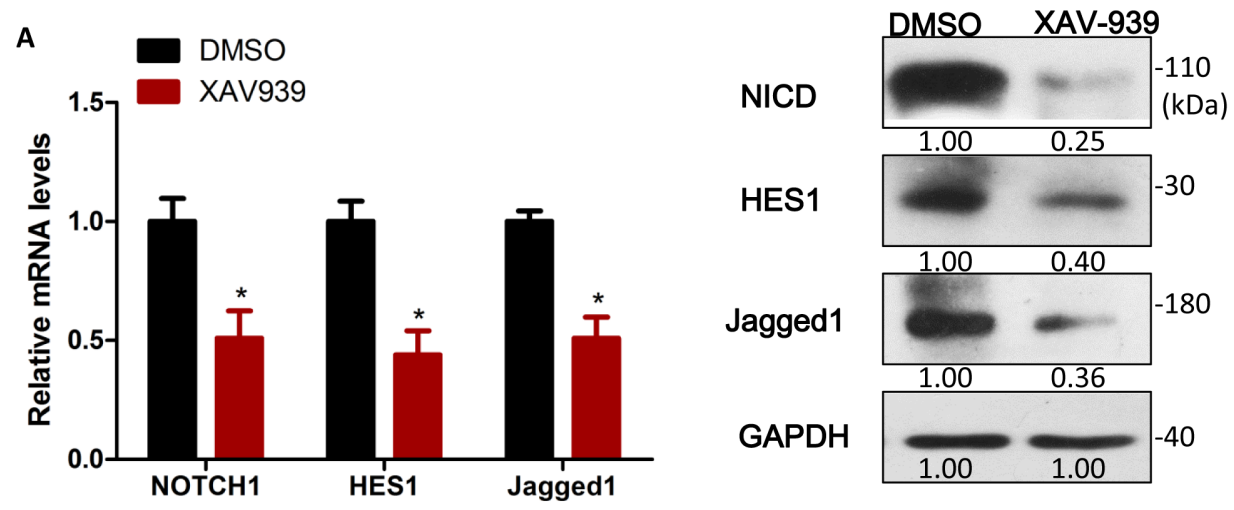

B
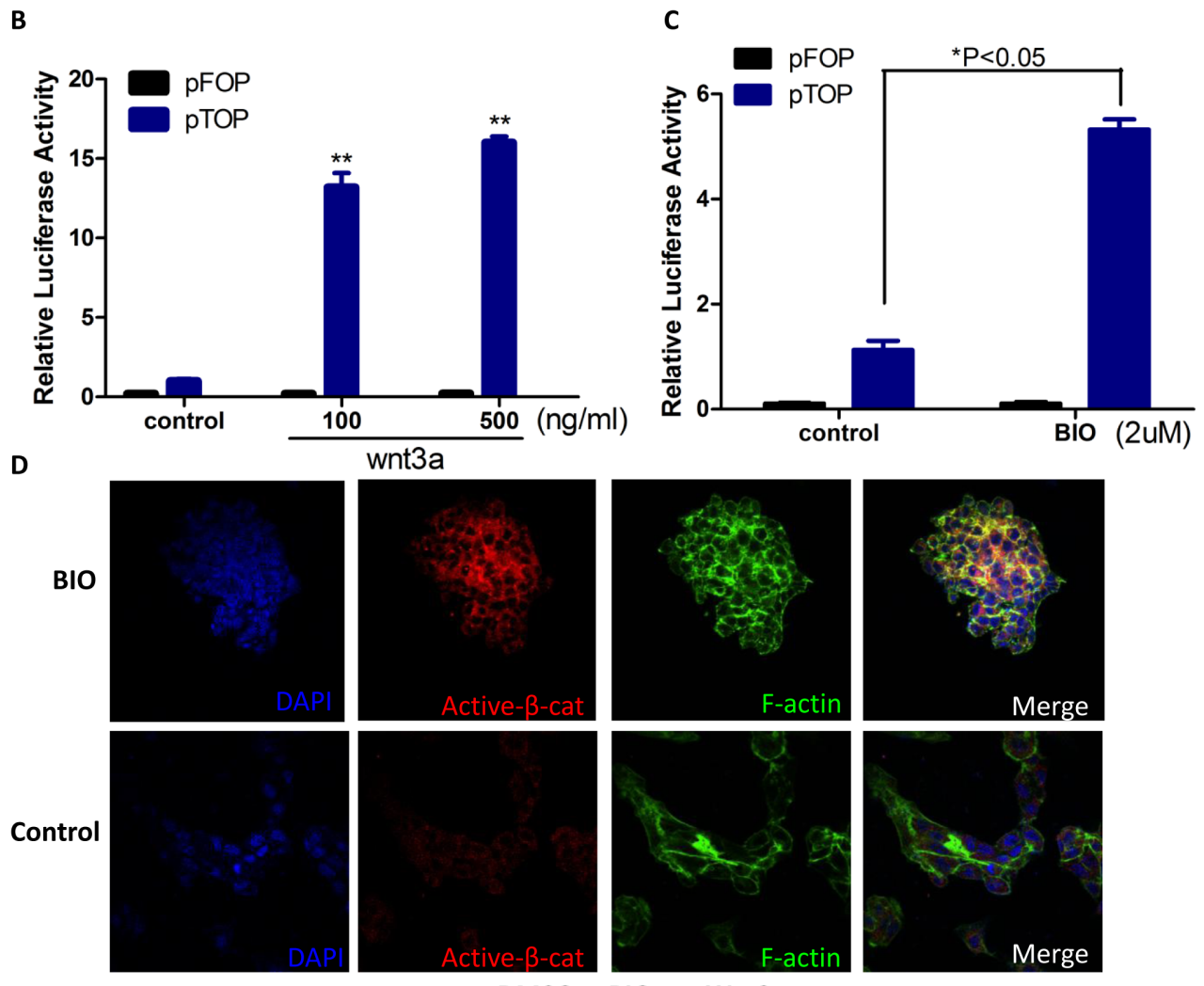

E

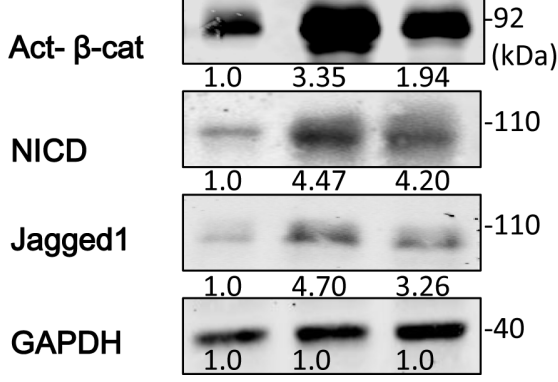

Figure 5: Notch1 was downstream of Wnt/ $\boldsymbol{\beta}$-catenin signaling in liver cancer stem cells. (A) Notch1 signaling pathway was dramatically down-regulated in set of the inhibition of Wnt/ $\beta$-catenin by XAV939. (B and $\mathbf{C}$ ) Relative $\beta$-catenin/TCF luciferase activity of sphere-forming LCSCs increased depending on the dosage of Wnt3a and BIO. (D) IF Staining of Active $\beta$-catenin accumulated in sphere-forming LCSCs when treat with BIO $(2 \mu \mathrm{M})$. (E) Notch1 signaling pathway was up-regulated upon the activation of Wnt/ $\beta$-catenin by Wnt3a $(100 \mathrm{ng} / \mathrm{ml})$ and BIO $(2 \mu \mathrm{M})$. All luciferase values were normalized to Renilla activity (mean $\pm \mathrm{SD} ; P<0: 01)$. $P$ values were determined using a two-tailed Student $t$-test, type II (see Methods). Gapdh antibody was used as a loading control. Numbers on western blots correspond to relative quantification. 
A

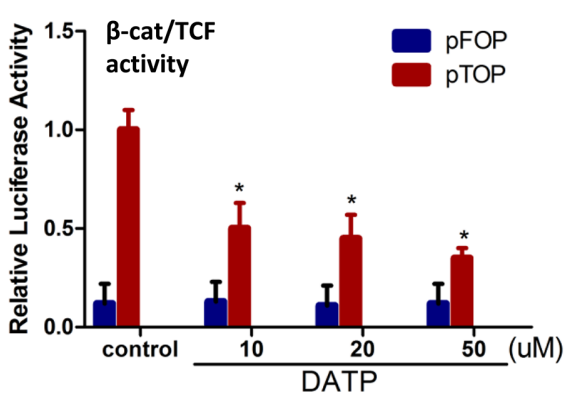

C

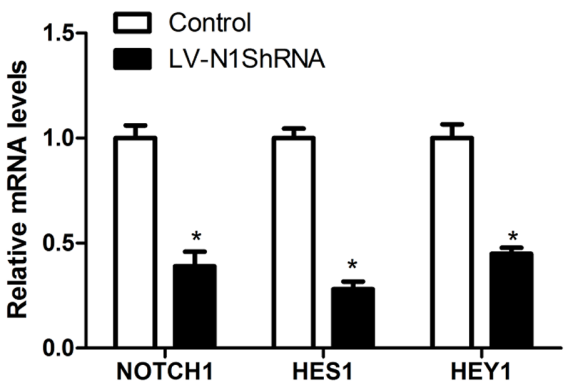

E

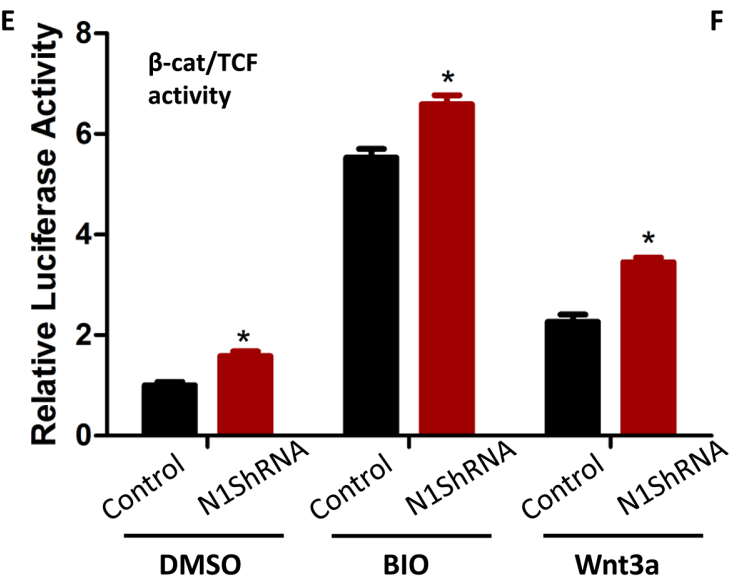

G

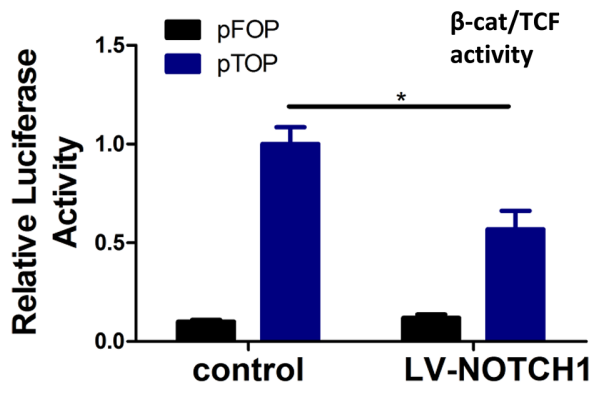

B

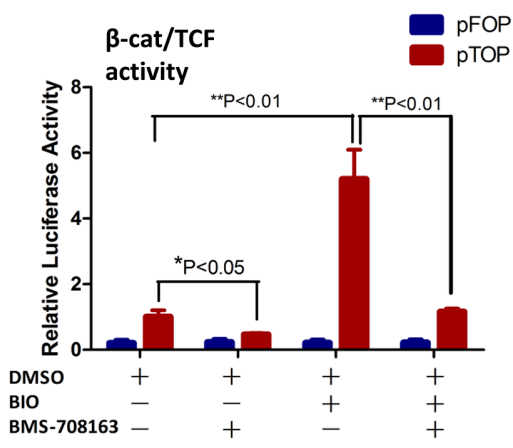

D

$\underline{\text { Control }} \frac{\text { LV-N1ShRNA }}{10 \quad 20(\mathrm{TU})}$
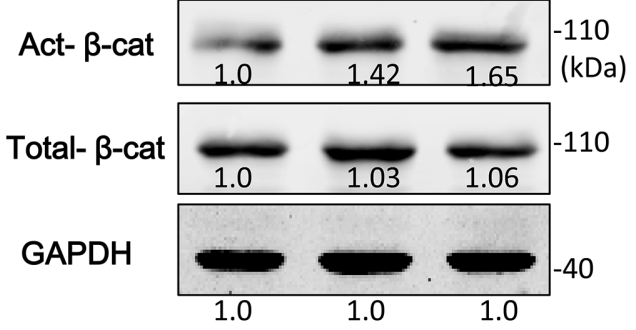

F

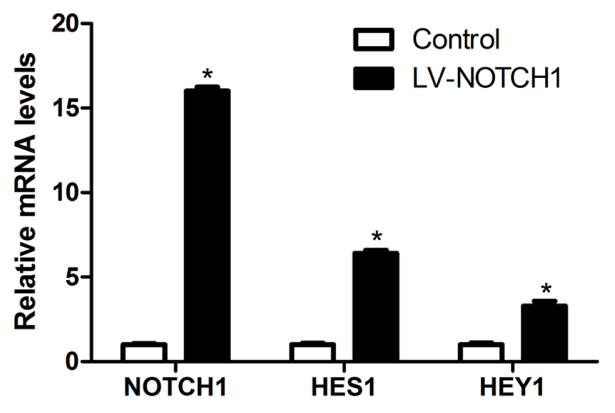

H

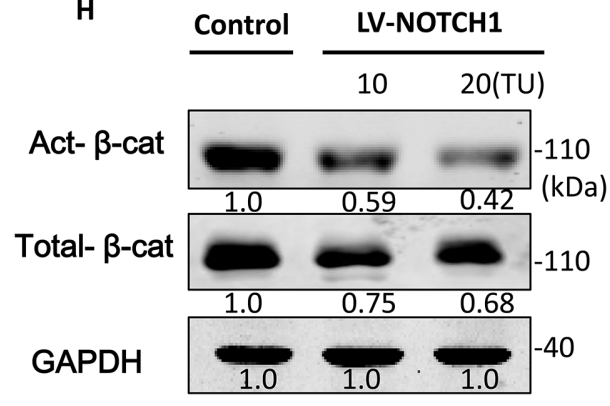

Figure 6: $\boldsymbol{\beta}$-catenin protein levels were diminished by Notch1 in liver cancer stem cells. (A) Relative $\beta$-catenin/TCF luciferase activity of LCSCs decreased when treated with increasing doses of DAPT for $48 \mathrm{~h}$. (B) The activation of Wnt/ $\beta$-catenin signaling by BIO $(2 \mu \mathrm{M})$ rescue $\gamma$-secretase inhibitor (BMS-708163)-induced suppression of $\beta$-catenin/TCF dependent luciferase activity. (C) Knockdown of Notch1 by LV-N1ShRNA. (D) Reduced Notch1 levels which knockout by LV-N1ShRNA increased the transcriptionally active form of $\beta$-catenin protein. (E) Relative $\beta$-catenin /TCF luciferase activity of sphere-forming LCSCs transfected with the control or LV-N1ShRNA in the presence or absence of BIO $(2 \mu \mathrm{M})$ or Wnt3a $(100 \mathrm{ng} / \mathrm{ml}$; mean $\pm \mathrm{SD} ; P<0: 01)$. (F) Notch1 was activited by LV-Notch1 after infected 48 h. (G) Relative $\beta$-catenin / TCF luciferase activity of sphere-forming LCSCs transfected with the control or actived Notch1 (NICD) construct, LV-Notch1. (H) active $\beta$-catenin protein levels increased after the over-expression of NICD by LV-Notch1. 
the inhibition of self-renewal of LCSCs induced by BrMC [44]. Consistently, we found increased Notch and $\mathrm{Wnt} / \beta$-catenin signaling pathway expression in the sphere-forming HCC cells. Inhibition of the Notch and Wnt/ $\beta$-catenin signaling pathways each significantly attenuated sphere formation, colony formation, tumor development, and metastasis to the lungs capacity in NOD/SCID mice. This result suggests that both pathways play important roles in tumor formation and metastasis capacity. Furthermore, the decrease in cancer stem cells surface markers phenotype (CD90, CD44, CD133, CD13 and CD24) observed in combined DATP and XAV939 was no more than that observed by either individual treatment, suggesting that Notch and $\mathrm{Wnt} / \beta$-Catenin may have cross-talk between each other.

Notch and Wnt/ $\beta$-Catenin signaling often intersect in stem and progenitor cells and regulate one another transcriptionally [45]. The effects between each other are highly controversial. Chulan et al recently demonstrated that Notch 1 antagonizes $\mathrm{Wnt} / \beta$-Catenin signaling by reducing levels of active $\beta$-Catenin in cardiac progenitor cells (CPCs) [27]. Conversely, the oncogenic effect of Notch 1 on primary melanoma cells was mediated by $\beta$-catenin, which was upregulated following Notch1 activation [46]. This is in line with our previous study that Notch signaling is upstream of the Wnt pathway in regulating proliferation of $\mathrm{L} 02 / \mathrm{HBx}$ cells [26]. In the present study, however, we discovered that Notch1 may be downstream of Wnt/ $\beta$-catenin signaling.
And Notch negatively regulates protein levels of active $\beta$-catenin in a post-translational manner in sphere-forming LCSCs. In our experiments, the interaction between these two critical regulatory proteins did not require liganddependent cleavage of Notch. Thus, in the presence of Wnt/ $\beta$-catenin signaling, Notch may serve to titrating active $\beta$-catenin levels to temper the proliferative state of expanding cells [27]. It is likely Notch functions as a governor to balance tumor cell proliferation and the maintenance of the CSC population by regulating the $\beta$-catenin pathway. Contradictory data existed in stem cells and liver cancer stem cells suggesting that the versatile effects of Notch signaling pathway often depends on the context and timing as cells progress through stages of differentiation.

In this study, we identified sphere-forming LCSCs (CD90CD24CD13CD133+/high) within these small lesions, and they functioned to initiate tumor growth and self-renewal through Notch and Wnt/ $\beta$-catenin upregulation. In addition, Notch1 was downstream of $\mathrm{Wnt} / \beta$-catenin. There may be a non-proteasome mediated feedback loop between Notch1 and Wnt/ $\beta$-catenin signaling in LCSCs (show in Figure 7). Although, the feedback loop between Notch1 and Wnt signaling need further study, the central role of Notch and Wnt/ $\beta$-catenin signaling pathway in tumors may provide an attractive therapeutic strategy against HCC.

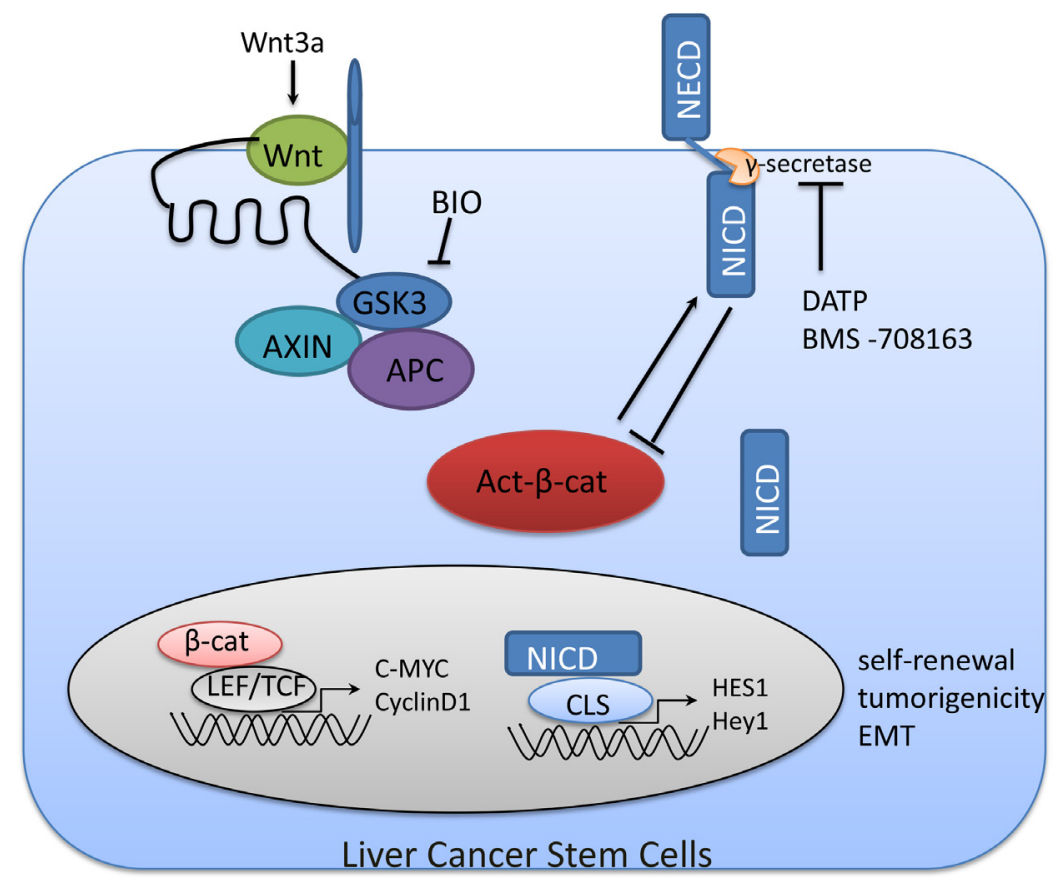

Figure 7: A non-proteasome mediated feedback loop between Notch1 and Wnt/ß-catenin signaling in LCSCs. The destruction complex in Wnt/ $\beta$-catenin signaling is composed of Axin, APC and GSK3 $\beta$. When the destruction complex of is inactivated by Wnt (Wnt3a) or BIO, dephosphorylated (active) $\beta$-catenin functions as a transcriptional activator with LEF/TCF. We show that Notch1 may be the downstream of $\mathrm{Wnt} / \beta$-catenin. Active $\beta$-catenin protein levels can be negatively regulated by interaction with Notch. NECD, Notch extracellular domain; NICD, Notch intracellular domain. 


\section{MATERIALS AND METHODS}

\section{Tissue collection and patient demographic information}

Samples of paraffin-embedded sections of HCC and adjacent liver specimens were obtained from $61 \mathrm{HCC}$ patients undergoing curative resection between 2008 and 2011 in Tongji hospital, Huazhong University of Science and Technology (HUST, Wuhan, China). Clinical data associated with those specimens was recorded without patient identification and all procedures were in accordance with the Huazhong University of Science and Technology Institutional Review Board protocols, and partial of human tissue samples. Informed consent was obtained from each subject. Patients were enrolled as described [47]. Survival data were determined at the last follow-up period for living patients. Tumor differentiation was defined according to the Edmondson grading system.

\section{Histology and immunohistochemistry}

The IHC stained Samples from patients with primary antibodies Rabbit monoclonal anti-CD90 / Thy1 (abcam, cat\# ab92574), Rabbit Monoclonal antiCD44 (ZSGE-BIO, cat\# ZA-0537), Rabbit Polyclonal anti-CD24 (abgent, cat\# \# AP8782a), Mouse monoclonal anti-CD13 (ZSGE-BIO, cat\# ZM-0284), Rabbit Polyclonal anti-CD133 (ZSGE-BIO, cat\# ZA-0426) following the manufacturer. And the IHC stained tissue sections (Supplementary Materials and Methods) were analyzed individually by three pathologists without the patients' clinical characteristics. Staining for CD90, CD44, CD24, CD13 and CD133 was assessed using a relatively simple, reproducible scoring method. The intensity of staining was scored on a four point scale as negative (0), weak (1), medium (2) or strong (3). The extent of the staining, defined as the percentage of positive staining areas of tumor cells in relation to the whole tumor area, was scored on a scale of 0 to $4: 0(0 \%), 1$ (1-25\%), 2 (26-50\%), 3 (51-75\%) and 4 (76-100\%), see [48]. An overall protein expression score (overall score range, $0-12$ ) was calculated by multiplying the intensity and positivity scores as described previously [49]. For statistical analysis, the final score was the mean value of scores from three observers. Scores $\leq 4$ were considered as low expression, whereas scores $\geq 5$ were considered as high expression. For statistical analysis, the final score was the mean value of scores from three observers. Examples of these are shown in Supplementary Figure S1.

\section{Cell lines and sphere culture}

Human HCC cell lines (PLC/PRF/5, Huh7 and SMMC-7721) were obtained from American Type of Culture Collection (ATCC) and Cell Bank of Chinese
Academy of Sciences (Shanghai, China). All of the cells were cultured as described [50]. For spheroid culture, cells were collected and washed to remove serum, then suspended in serum-free DMEM/F12 medium (cat\#12400-024, GIBCO, Grand Island, NY) with B27 supplement (cat\#17504-044; GIBCO, Grand Island, NY), $100 \mathrm{IU} / \mathrm{ml}$ penicillin, $100 \mu \mathrm{g} / \mathrm{ml}$ streptomycin, $20 \mathrm{ng} / \mathrm{ml}$ human recombinant epidermal growth factor (EGF, cat\#PHG0311; GIBCO), $10 \mathrm{ng} / \mathrm{ml}$ human recombinant basic fibroblast growth factor (bFGF, cat\#PHG0266; GIBCO), 2\% B27 supplement without vitamin A, 1\% N-2 supplement (cat\#17502-048; GIBCO, Carlsbad, CA, USA) and 1\% methyl cellulose(cat\#M0262; Sigma-Aldrich) preventing cell aggregation. The cells were subsequently cultured in $100 \mathrm{~mm}$ ultra-low attachment dishes (cat\#3262, Corning Life Sciences, Oneonta, NY, USA) at a density of $10^{4}$ cells $/ 10 \mathrm{ml}$.

\section{Lentiviral-based transfection into HCC cells}

For suppression or inhibition of Notch in HCC cells, lentiviral particles (Genechem, Shanghai) expressing Notch1-siRNA or NICD were used to regulate Notch signaling in sorted HCC cells. The siRNA sequence targeted Notch1 was listed as follows: 5'-GGAGCATGTGTAACATCAA-3'. For optimization of transfection conditions with lentiviral vectors, HCC cells were infected with Lv-NICD or Lv-Notch1-si at different of multiplicity of infection (MOI) for 12 hours in the presence of $5 \mu \mathrm{g} / \mathrm{ml}$ of polybrene. Two days after infection, expression of green florescence protein was measured by FACS analysis. Infection of cells at MOI of 10 resulted in more than $90 \%$ of efficiency of infection without damaging cells (not shown in data).

\section{Luciferase reporter assay}

For the TCF activity assay, pSUPER $8 \times$ TOPFlash or pSUPER8xFOPFlash (Addgene) and Renilla plasmids, kindly provided by Dr. Timothy R. Billiar (From the Department of Surgery, University of Pittsburgh School of Medicine, Pittsburgh), were co-transfected into HCC cells. Twenty-four hours after transfection, the cells were serumstarved for $24 \mathrm{~h}$ and stimulated with 1\% FBS in DMEM. Luciferase activity was measured at $24 \mathrm{~h}$ after stimulation unless indicated using the Luciferase Assay System (Promega, Madison, MI). The assay was normalized with renilla as a transfection efficiency control.

\section{Statistical analysis}

Statistical analysis and graphical presentation were performed using SPSS (v19.0) software for Windows (SPSS Inc., Chicago, IL). The logistic regression model was utilized to analyze the clinic-pathological parameters which were compared with log-rank test. The Cox 
regression model was used to perform univariate and multivariate analyses. The survival rate was calculated using the Kaplan-Meier method, and the resulting curves were compared by the log -rank test. $P<0.05$ was considered significant. Other data in cell experiment are presented as mean \pm standard deviation. When two groups were com-pared, the Student's $t$ test was used. $P<0.05$ was considered significant statistically and is marked with an asterisk. $P<0.01$ was considered highly significant statistically and is marked with a double asterisk.

\section{ACKNOWLEDGMENTS}

The authors thank Zhong Guo (Faculty in Department of Surgery, University of Pittsburgh School of Medicine, Pittsburgh, Pennsylvania) for reviewing the article.

\section{GRANT SUPPORT}

This work was supported by the National Science Foundation of China (No. 81172063 and No. 81372352) and Innovation Foundation of Huazhong University of Science and Technology. Note: Ronghua Wang was supported by China Scholarship Association.

\section{CONFLICTS OF INTEREST}

The authors declare that there is no conflicts of interest with any financial organization or corporation or individual that can inappropriately influence this work.

\section{REFERENCES}

1. Llovet JM, Bruix J. Systematic review of randomized trials for unresectable hepatocellular carcinoma: Chemoembolization improves survival. Hepatology. 2003; 37:429-442.

2. Dalerba P, Clarke MF. Cancer stem cells and tumor metastasis: first steps into uncharted territory. Cell stem cell. 2007; 1:241-242.

3. Abdalla EK, Pisters PW. Staging and preoperative evaluation of upper gastrointestinal malignancies. Seminars in oncology. 2004; 31:513-529.

4. Tesche LJ, Gerber DA. Tissue-derived stem and progenitor cells. Stem cells international. 2010; 2010:824876.

5. Walkup MH, Gerber DA. Hepatic stem cells: in search of. Stem cells. 2006; 24:1833-1840.

6. Ma S, Tang KH, Chan YP, Lee TK, Kwan PS, Castilho A, Ng I, Man K, Wong N, To KF, Zheng BJ, Lai PB, Lo CM, et al. miR-130b Promotes CD133(+) liver tumor-initiating cell growth and self-renewal via tumor protein 53-induced nuclear protein 1. Cell stem cell. 2010; 7:694-707.
7. Yang ZF, Ho DW, Ng MN, Lau CK, Yu WC, Ngai P, Chu PW, Lam CT, Poon RT, Fan ST. Significance of CD90+ cancer stem cells in human liver cancer. Cancer cell. 2008; 13:153-166.

8. Haraguchi N, Ishii H, Mimori K, Tanaka F, Ohkuma M, Kim HM, Akita H, Takiuchi D, Hatano H, Nagano H, Barnard GF, Doki Y, Mori M. CD13 is a therapeutic target in human liver cancer stem cells. The Journal of clinical investigation. 2010; 120:3326-3339.

9. Lee TK, Castilho A, Cheung VC, Tang KH, Ma S, Ng IO. CD24(+) liver tumor-initiating cells drive self-renewal and tumor initiation through STAT3-mediated NANOG regulation. Cell stem cell. 2011; 9:50-63.

10. Wan S, Zhao E, Kryczek I, Vatan L, Sadovskaya A, Ludema G, Simeone DM, Zou W, Welling TH. Tumor-associated macrophages produce interleukin 6 and signal via STAT3 to promote expansion of human hepatocellular carcinoma stem cells. Gastroenterology. 2014; 147:1393-1404.

11. Yamashita T, Ji J, Budhu A, Forgues M, Yang W, Wang HY, Jia H, Ye Q, Qin LX, Wauthier E, Reid LM, Minato H, Honda M, et al. EpCAM-positive hepatocellular carcinoma cells are tumor-initiating cells with stem/progenitor cell features. Gastroenterology. 2009; 136:1012-1024.

12. Al-Hajj M, Wicha MS, Benito-Hernandez A, Morrison SJ, Clarke MF. Prospective identification of tumorigenic breast cancer cells. Proceedings of the National Academy of Sciences of the United States of America. 2003; 100:3983-3988.

13. Li C, Lee CJ, Simeone DM. Identification of human pancreatic cancer stem cells. Methods in molecular biology. 2009; 568:161-173.

14. Noh KH, Lee YH, Jeon JH, Kang TH, Mao CP, Wu TC, Kim TW. Cancer vaccination drives Nanog-dependent evolution of tumor cells toward an immune-resistant and stem-like phenotype. Cancer research. 2012; 72:1717-1727.

15. Dontu G, Jackson KW, McNicholas E, Kawamura MJ, Abdallah WM, Wicha MS. Role of Notch signaling in cellfate determination of human mammary stem/progenitor cells. Breast cancer research. 2004; 6:R605-615.

16. Liu S, Dontu G, Mantle ID, Patel S, Ahn NS, Jackson KW, Suri $\mathrm{P}$, Wicha MS. Hedgehog signaling and Bmi-1 regulate self-renewal of normal and malignant human mammary stem cells. Cancer research. 2006; 66:6063-6071.

17. Gedaly R, Galuppo R, Daily MF, Shah M, Maynard E, Chen C, Zhang X, Esser KA, Cohen DA, Evers BM, Jiang J, Spear BT. Targeting the Wnt/beta-catenin signaling pathway in liver cancer stem cells and hepatocellular carcinoma cell lines with FH535. PloS one. 2014; 9:e99272.

18. Jin C, Samuelson L, Cui CB, Sun Y, Gerber DA. MAPK/ ERK and Wnt/beta-Catenin pathways are synergistically involved in proliferation of Sca-1 positive hepatic progenitor cells. Biochemical and biophysical research communications. 2011; 409:803-807. 
19. Lachenmayer A, Alsinet C, Savic R, Cabellos L, Toffanin S, Hoshida Y, Villanueva A, Minguez B, Newell P, Tsai HW, Barretina J, Thung S, Ward SC, et al. Wnt-pathway activation in two molecular classes of hepatocellular carcinoma and experimental modulation by sorafenib. Clinical cancer research. 2012; 18:4997-5007.

20. Zhang XP, Zheng G, Zou L, Liu HL, Hou LH, Zhou P, Yin DD, Zheng QJ, Liang L, Zhang SZ, Feng L, Yao LB, Yang AG, et al. Notch activation promotes cell proliferation and the formation of neural stem cell-like colonies in human glioma cells. Molecular and cellular biochemistry. 2008; 307:101108.

21. Winton DJ. miR-34a sets the "sweet spot" for notch in colorectal cancer stem cells. Cell stem cell. 2013; 12:499-501.

22. Zhao D, Mo Y, Li MT, Zou SW, Cheng ZL, Sun YP, Xiong Y, Guan KL, Lei QY. NOTCH-induced aldehyde dehydrogenase 1A1 deacetylation promotes breast cancer stem cells. The Journal of clinical investigation. 2014; 124:5453-5465.

23. Yamashita T, Budhu A, Forgues M, Wang XW. Activation of hepatic stem cell marker EpCAM by Wnt-beta-catenin signaling in hepatocellular carcinoma. Cancer research. 2007; 67:10831-10839.

24. Malanchi I, Peinado H, Kassen D, Hussenet T, Metzger D, Chambon P, Huber M, HohlD, Cano A, BirchmeierW, Huelsken J. Cutaneous cancer stem cell maintenance is dependent on betacatenin signalling. Nature. 2008; 452:650-653.

25. Vermeulen L, De Sousa EMF, van der Heijden M, Cameron K, de Jong JH, Borovski T, Tuynman JB, Todaro M, Merz C, Rodermond H, Sprick MR, Kemper K, Richel DJ, et al. Wnt activity defines colon cancer stem cells and is regulated by the microenvironment. Nature cell biology. 2010; 12:468-476.

26. Sun Q, Wang R, Luo J, Wang P, Xiong S, Liu M, Cheng B. Notch1 promotes hepatitis $\mathrm{B}$ virus $\mathrm{X}$ protein-induced hepatocarcinogenesis via Wnt/beta-catenin pathway. International journal of oncology. 2014; 45:1638-1648.

27. Kwon C, Cheng P, King IN, Andersen P, Shenje L, Nigam V, Srivastava D. Notch post-translationally regulates betacatenin protein in stem and progenitor cells. Nature cell biology. 2011; 13:1244-1251.

28. Rodilla V, Villanueva A, Obrador-Hevia A, Robert-Moreno A, Fernandez-Majada V, Grilli A, Lopez-Bigas N, Bellora N, Alba MM, Torres F, Dunach M, Sanjuan X, Gonzalez S, et al. Jagged1 is the pathological link between Wnt and Notch pathways in colorectal cancer. Proceedings of the National Academy of Sciences of the United States of America. 2009; 106:6315-6320.

29. Patrawala L, Calhoun T, Schneider-Broussard R, Zhou J, Claypool K, Tang DG. Side population is enriched in tumorigenic, stem-like cancer cells, whereas ABCG2+ and ABCG2- cancer cells are similarly tumorigenic. Cancer research. 2005; 65:6207-6219.

30. Li C, Heidt DG, Dalerba P, Burant CF, Zhang L, Adsay V, Wicha M, Clarke MF, Simeone DM. Identification of pancreatic cancer stem cells. Cancer research. 2007; 67:1030-1037.
31. Friel AM, Sergent PA, Patnaude C, Szotek PP, Oliva E, Scadden DT, Seiden MV, Foster R, Rueda BR. Functional analyses of the cancer stem cell-like properties of human endometrial tumor initiating cells. Cell cycle. 2008; 7:242-249.

32. Abubaker K, Luwor RB, Zhu H, McNally O, Quinn MA, Burns CJ, Thompson EW, Findlay JK, Ahmed N. Inhibition of the JAK2/STAT3 pathway in ovarian cancer results in the loss of cancer stem cell-like characteristics and a reduced tumor burden. BMC cancer. 2014; 14:317.

33. Koo BS, Lee SH, Kim JM, Huang S, Kim SH, Rho YS, Bae WJ, Kang HJ, Kim YS, Moon JH, Lim YC. Oct4 is a critical regulator of stemness in head and neck squamous carcinoma cells. Oncogene. 2015; 34:2317-24.

34. Boumahdi S, Driessens G, Lapouge G, Rorive S, Nassar D, Le Mercier M, Delatte B, Caauwe A, Lenglez S, Nkusi E, Brohee S, Salmon I, Dubois C, et al. SOX2 controls tumour initiation and cancer stem-cell functions in squamous-cell carcinoma. Nature. 2014; 511:246-250.

35. Chiba T, Miyagi S, Saraya A, Aoki R, Seki A, Morita Y, Yonemitsu Y, Yokosuka O, Taniguchi H, Nakauchi H, Iwama A. The polycomb gene product BMI1 contributes to the maintenance of tumor-initiating side population cells in hepatocellular carcinoma. Cancer research. 2008; 68: 7742-7749.

36. Arii S, Tanaka J, Yamazoe Y, Minematsu S, Morino T, Fujita K, Maetani S, Tobe T. Predictive factors for intrahepatic recurrence of hepatocellular carcinoma after partial hepatectomy. Cancer. 1992; 69:913-919.

37. Roayaie S, Blume IN, Thung SN, Guido M, Fiel MI, Hiotis S, Labow DM, Llovet JM, Schwartz ME. A system of classifying microvascular invasion to predict outcome after resection in patients with hepatocellular carcinoma. Gastroenterology. 2009; 137:850-855.

38. Su G, Zhao Y, Wei J, Han J, Chen L, Xiao Z, Chen B, Dai J. The effect of forced growth of cells into 3D spheres using low attachment surfaces on the acquisition of stemness properties. Biomaterials. 2013; 34:3215-3222.

39. Cao L, Zhou Y, Zhai B, Liao J, Xu W, Zhang R, Li J, Zhang Y, Chen L, Qian H, Wu M, Yin Z. Sphere-forming cell subpopulations with cancer stem cell properties in human hepatoma cell lines. BMC gastroenterology. 2011; 11:71.

40. Wang L, Guo H, Yang L, Dong L, Lin C, Zhang J, Lin P, Wang X. Morusin inhibits human cervical cancer stem cell growth and migration through attenuation of NF-kappaB activity and apoptosis induction. Molecular and cellular biochemistry. 2013; 379:7-18.

41. Zhang Q, Lu C, Fang T, Wang Y, Hu W, Qiao J, Liu B, Liu J, Chen N, Li M, Zhu R. Notch3 functions as a regulator of cell self-renewal by interacting with the beta-catenin pathway in hepatocellular carcinoma. Oncotarget. 2015; 6:3669-3679. doi: 10.18632/oncotarget.2898.

42. Wong NK, Fuller M, Sung S, Wong F, Karsan A. Heterogeneity of breast cancer stem cells as evidenced 
with Notch-dependent and Notch-independent populations. Cancer medicine. 2012; 1:105-113.

43. Mao J, Fan S, Ma W, Fan P, Wang B, Zhang J, Wang H, Tang B, Zhang Q, Yu X, Wang L, Song B, Li L. Roles of Wnt/beta-catenin signaling in the gastric cancer stem cells proliferation and salinomycin treatment. Cell death \& disease. 2014; 5:e1039.

44. Quan MF, Xiao LH, Liu ZH, Guo H, Ren KQ, Liu F, Cao JG, Deng XY. 8-bromo-7-methoxychrysin inhibits properties of liver cancer stem cells via downregulation of beta-catenin. World journal of gastroenterology. 2013; 19:7680-7695.

45. Liu S, Dontu G, Wicha MS. Mammary stem cells, selfrenewal pathways, and carcinogenesis. Breast cancer research. 2005; 7:86-95.

46. Balint K, Xiao M, Pinnix CC, Soma A, Veres I, Juhasz I, Brown EJ, Capobianco AJ, Herlyn M, Liu ZJ. Activation of Notch1 signaling is required for beta-catenin-mediated human primary melanoma progression. The Journal of clinical investigation. 2005; 115:3166-3176.
47. Fan ST, Lo CM, Liu CL, Lam CM, Yuen WK, Yeung C, Wong J. Hepatectomy for hepatocellular carcinoma: toward zero hospital deaths. Annals of surgery. 1999; 229:322-330.

48. Zeng Z, Ren J, O’Neil M, Zhao J, Bridges B, Cox J, Abdulkarim B, Schmitt TM, Kumer SC, Weinman SA. Impact of stem cell marker expression on recurrence of TACE-treated hepatocellular carcinoma post liver transplantation. BMC cancer. 2012; 12:584.

49. Shan J, Shen J, Liu L, Xia F, Xu C, Duan G, Xu Y, Ma Q, Yang Z, Zhang Q, Ma L, Liu J, Xu S, et al. Nanog regulates self-renewal of cancer stem cells through the insulin-like growth factor pathway in human hepatocellular carcinoma. Hepatology. 2012; 56:1004-1014.

50. Luo J, Zhou H, Wang F, Xia X, Sun Q, Wang R, Cheng B. The hepatitis B virus X protein downregulates NF-kappaB signaling pathways through decreasing the Notch signaling pathway in HBx-transformed L02 cells. International journal of oncology. 2013; 42:1636-1643. 